\title{
Summarizing and exploring data of a decade of cytokinin-related transcriptomics
}

\author{
Wolfram G. Brenner* and Thomas Schmülling * \\ Dahlem Centre of Plant Sciences, Institute of Biology/Applied Genetics, Freie Universität Berlin, Berlin, Germany
}

\author{
Edited by: \\ Mariana Benitez, Universidad \\ Nacional Autónoma de México, \\ Mexico \\ Reviewed by: \\ Aaron M. Rashotte, Auburn \\ University, USA \\ Jan Hejatko, Masaryk University, \\ Czech Republic \\ *Correspondence: \\ Wolfram G. Brenner and Thomas \\ Schmülling, Dahlem Centre of Plant \\ Sciences, Institute of \\ Biology/Applied Genetics, Freie \\ Universität Berlin, \\ Albrecht-Thaer-Weg 6, D-14195 \\ Berlin, Germany \\ e-mail:wbrenne@zedat.fu-berlin.de; \\ tschmue@zedat.fu-berlin.de
}

\begin{abstract}
The genome-wide transcriptional response of the model organism Arabidopsis thaliana to cytokinin has been investigated by different research groups as soon as large-scale transcriptomic techniques became affordable. Over the last 10 years many transcriptomic datasets related to cytokinin have been generated using different technological platforms, some of which are published only in databases, culminating in an RNA sequencing experiment. Two approaches have been made to establish a core set of cytokinin-regulated transcripts by meta-analysis of these datasets using different preferences regarding their selection. Here we add another meta-analysis derived from an independent microarray platform (CATMA), combine all the meta-analyses available with RNAseq data in order to establish an advanced core set of cytokinin-regulated transcripts, and compare the results with the regulation of orthologous rice genes by cytokinin. We discuss the functions of some of the less known cytokinin-regulated genes indicating areas deserving further research to explore cytokinin function. Finally, we investigate the promoters of the core set of cytokinin-induced genes for the abundance and distribution of known cytokinin-responsive cis elements and identify a set of novel candidate motifs.
\end{abstract}

Keywords: cytokinin, cis element, gene regulation, hormone action, meta-analysis, regulatory network, signal transduction, transcriptomics

\section{INTRODUCTION}

Cytokinins are a class of plant hormones with a broad range of functions in regulating plant growth and development as well as physiologicial processes (Werner and Schmülling, 2009; Kieber and Schaller, 2014). In Arabidopsis thaliana, they are perceived by three closely related receptors localized mainly at the ER membrane (Heyl et al., 2012). Perception of cytokinins by the receptors triggers a multistep His-Asp phosphorelay signal transduction chain transducing the signal to the nucleus, where a set of MYB-like transcription factors, the type-B response regulators, are activated to induce the transcription of their target genes (Sakai et al., 2000; Hwang et al., 2002). Among the direct targets are type-A response regulator genes, which encode negative regulators of the upstream signal transduction system (Hwang and Sheen, 2001). Additionally, a set of transcription factors of the ERF/AP2 family is involved in mediating the response to cytokinins, named cytokinin response factors (CRFs) (Rashotte et al., 2006).

The genome-wide transcriptional response of Arabidopsis thaliana to cytokinins was investigated by different research groups as soon as large-scale transcriptomics became affordable. The flood of data started in 2002 with a publication addressing shoot induction in calli by cytokinin (Che et al., 2002), followed by two studies dedicated to cytokinin induction in seedlings (Rashotte et al., 2003; Brenner et al., 2005), the latter using the full genome ATH1 GeneChip ${ }^{\circledR}$, and a study focusing on the response regulator ARR22 (Kiba et al., 2004). Since then, many more large-scale transcriptomic datasets related to cytokinin have been generated using different technological platforms, some of which are published only in databases (Brenner et al., 2012), culminating in an RNA sequencing experiment (Bhargava et al., 2013). All of the microarray studies, however, suffer from the noisy nature of the data generated by this hybridization-based method, potentially resulting in a substantial number of false positives and negatives. An attempt to identify a core set of cytokinin-regulated genes has been made using a single microarray dataset and applying elaborate statistical methods in order to narrow down the number of genes (Nemhauser et al., 2006). This attempt, however, relying on only one single microarray experiment, was tained with the inevitable insecurities inherent to the technology and prone to contain false positive genes. The obvious solution to overcome this problem is to extend the database. Meta-analysis, the statistical summary of many studies on the same subject, can be used to increase the statistical power beyond that of individual studies (De Magalhães et al., 2009; Plank et al., 2012). Two approaches to establish a core set of cytokinin-regulated transcripts by meta-analysis of transcriptomic data using different preferences regarding the datasets used have been published (Brenner et al., 2012; Bhargava et al., 2013).

The nature of the promoters of cytokinin-inducible genes has drawn interest since the discovery that type- $\mathrm{B}$ response regulators realize the immediate early transcriptional output of the cytokinin signal transduction chain. The sequence (A/G) GAC (C/T) was identified as the ARR1-binding DNA motif (Sakai et al., 2000, 2001), which was later named cytokinin response motif (CRM) (Ramireddy et al., 2013). The CRM 
was more precisely characterized leading to the octameric motif AAGAT(C/T)TT (Taniguchi et al., 2007) named extended CRM (ECRM) by Ramireddy et al. (2013). Based on this knowledge, the promoter of ARR6 was thoroughly investigated, and it was found that all of the four ECRM variants within 350 bp upstream of the transcription start site contribute to a different degree to the promoter's cytokinin responsiveness and to its response toward different type-B response regulators (Ramireddy et al., 2013). However, it was noted that the promoters of numerous known cytokinin responsive genes lack an ECRM. It may be that functional ECRM variants are located further upstream than the $-1000 \mathrm{bp}$ sequences analyzed or within the transcribed region of the genes. However, since most functionally relevant cis-elements are located within a distance of $-500 \mathrm{bp}$ upstream of the transcription start site (Franco-Zorrilla et al., 2014), we would expect that this is not often the case. This observation may rather suggest that there must be additional DNA sequences mediating a cytokinin response.

In this publication, we add another meta-analysis of cytokinin response genes derived from an independent microarray platform. All the available meta-analyses and the RNA sequencing data have been compared to establish an advanced core set of cytokinin-regulated transcripts. In addition, the identification of evolutionary conserved regulation of orthologous rice genes by cytokinin is reported. The identity of these genes indicates promising directions of future research into areas which have not yet been functionally linked to cytokinin activity. The promoter sequences of core set genes have been analyzed leading to the proposal of putative novel cytokinin response motifs.

\section{MATERIALS AND METHODS \\ CATMA MICROARRAY META-ANALYSIS}

CATMA microarray hybridization and data processing were described before (Brenner and Schmülling, 2012; Ramireddy et al., 2013). Meta-analysis of the set of four datasets, two of which were published (Brenner and Schmülling, 2012; Ramireddy et al., 2013) was performed as described (Brenner et al., 2012). Calculation of average expression values, sorting and filtering of the data were carried out in Microsoft Excel. The individual datasets are accessible in the ArrayExpress database (http:// www.ebi.ac.uk/arrayexpress/) under the accessions E-MEXP-670, E-CAGE-111, E-MEXP-689, and E-CAGE-49.

\section{COMPARATIVE OVERLAP ANALYSIS OF LARGE-SCALE TRANSCRIPTOMIC DATASETS RELATED TO CYTOKININ}

Four data sources were used for the comparative analysis: (1) The meta-analysis of CATMA microarray results presented in this study; (2) a meta-analysis of publicly available datasets performed with the Affymetrix ATH1 gene chip focusing on studies with a similar experimental layout (Brenner et al., 2012); (3) a meta-analysis of publicly available datasets performed with the Affymetrix ATH1 gene chip based on a more broadly selected dataset (Bhargava et al., 2013); and (4) a global gene expression analysis in response to cytokinin using RNA sequencing (Bhargava et al., 2013). The datasets were compared using an overlap analysis, and the results were plotted as Venn diagrams.

\section{COMPUTATIONAL ANALYSIS OF ANNOTATED GENE FUNCTIONS}

Quantification of the major GO categories was carried out using the GO annotation search, functional categorization and download service at TAIR (http://www.arabidopsis.org/tools/ bulk/go/index.jsp). Detailed GO term enrichment was carried out using the AmiGO tool (http://amigol.geneontology.org/cgi-bin/ amigo/blast.cgi).

\section{PROMOTER ANALYSIS}

The $-1000 \mathrm{bp}$ sequences of the advanced core set of cytokinin-induced genes were downloaded from TAIR using the bulk data retrieval tool (http://www.arabidopsis.org/tools/ bulk/sequences/index.jsp). Motif mapping was carried out using the Toucan2 suite of sequence analysis tools (https://gbiomed. kuleuven.be/apps/lcb/toucan/toucan.jnlp) (Aerts et al., 2003, 2005). Degenerated motifs were counted with the help of a selfmade program written in Microsoft Visual Basic for Applications (Supplementary Text). Statistical evaluation of these results were carried out using Microsoft Excel. The consensus logo of the motifs found was generated using the weblogo service at Berkeley university (http://weblogo.berkeley.edu/) (Schneider and Stephens, 1990; Crooks et al., 2004).

\section{ANALYSIS OF CYTOKININ-RELATED TRANSCRIPTOMIC DATA FROM RICE}

The raw data of three transcriptomic datasets from rice with the accessions GSE6719, GSE37557, and GSE55902 were downloaded from the GEO database (http://www.ncbi.nlm.nih.gov/ geo/). GSE6719 contains data from root and leaf samples of the cultivar Nipponbare treated with $5 \mu \mathrm{M}$ trans-zeatin for 30 or $120 \mathrm{~min}$, respectively. GSE37557 is a series of different hormone treatments, from which we selected only the data from cytokinin treatment which were obtained from 7-day-old seedlings of the cultivar IR6 4 treated with $50 \mu \mathrm{M}$ benzyl adenine (BA) for $3 \mathrm{~h}$. The data of GSE55902 are from samples of the third leaf of 30day-old plants of cultivar Nagina22 treated for $72 \mathrm{~h}$ in darkness with $2 \mathrm{mg} / \mathrm{mL}$ BA. The data were normalized with the RMA algorithm using the Bioconductor affy package (Gautier et al., 2004; Gentleman et al., 2004). Fold-changes, $p$-values and FDRcorrected $q$-values (Benjamini and Hochberg, 1995) were calculated using Microsoft Excel. Significantly differentially expressed genes (differential expression $\geq 2$-fold, $q \leq 0.05$ ) were also identified in Excel. One dataset (GSE37557) gave no meaningful data for the cytokinin-induced samples. Therefore, the analysis was continued with the two remaining datasets and no meta-analysis was performed with the rice data.

\section{IDENTIFICATION OF RICE ORTHOLOGS OF ARABIDOPSIS GENES AND DETERMINATION OF THEIR TRANSCRIPTIONAL REGULATION BY CYTOKININ}

We employed two methods for the identification of rice orthologs of Arabidopsis genes. Firstly, we used reciprocal BLAST, where in the first step the rice database was queried with Arabidopsis protein sequences. In the second step, the Arabidopsis database was queried with the top results of the first search until the original Arabidopsis protein was no longer the top hit of the resulting list. All rice genes corresponding to those proteins 
yielding the Arabidopsis protein encoded by a cytokininregulated gene as the most closely related rice counterpart were classified as orthologs. Secondly, we used the service for retrieving rice orthologs for Arabidopsis genes (http://www.rothamsted. ac.uk/ppets/modperl/ets2/at_template_form.pl?config=Wheat) at PpETS (http://www.rothamsted.ac.uk/ppets/modperl/index. pl) (Mitchell et al., 2007). We combined the partially overlapping (20\%) results of both searches and analyzed the cytokinin response of these genes in the microarray data described above.

\section{RESULTS AND DISCUSSION META-ANALYSIS OF CYTOKININ-RELATED TRANSCRIPTOMIC DATA COLLECTED BY THE CATMA MICROARRAY}

The CATMA microarray is a cDNA microarray designed by a European consortium in the early 2000s to achieve the best possible gene coverage (Crowe et al., 2003; Hilson et al., 2003). To achieve this, gene-specific probes-so-called GSTs (gene-specific tags)—-were identified bioinformatically to cover the region of each transcript that is least similar to any other transcript in the transcriptome. These regions were amplified by PCR using a two-step process and spotted onto microarrays. The advantage of this microarray over the popular and widely used Affymetrix ATH1 array is that it is based on a more advanced genome annotation called EuGène (Schiex et al., 2001), therefore containing an improved representation of the Arabidopsis transcriptome. Its competitive performance in comparison to the Affymetrix and Agilent platforms has been demonstrated (Allemeersch et al., 2005). Cytokinin-related transcriptome studies using the CATMA microarray have been published before (Heyl et al., 2008; Brenner and Schmülling, 2012; Ramireddy et al., 2013), but the full amount of cytokinin-related data retrieved from this technology has not yet been evaluated. To get an overview over the full dataset we conducted a meta-analysis using the same approach as used before to evaluate publicly available ATH1 array data (Brenner et al., 2012). The top 25 induced transcripts are shown in Table 1 and the result of the entire analysis is available in Supplementary Table 1. A number of previously unknown genes was found to be regulated by cytokinin in the CATMA microarray metaanalysis, which, due to the statistical power of four summarized microarray studies represents a robust dataset. The result of this meta-analysis will be compared with results obtained the ATH1 microarray and RNA sequencing data in the following sections.

\section{COMPARISON OF RECENT META-ANALYSES AND LARGE-SCALE RNA SEQUENCING DATASETS}

Each of the technological platforms used for obtaining transcriptomic data-Affymetrix microarrays, CATMA microarrays, and RNA sequencing-has its specific benefits and weaknesses. In order to reduce biases introduced by the technologies themselves, we compared the datasets listed in Figure 1 using an overlap analysis (Figure 1).

The first obvious observation is that both the RNA sequencing data and the CATMA data contain many unique genes (68 and $80 \%$, respectively) and have a small overlap $(<11 \%)$ whereas the two datasets from meta-analyses of Affymetrix ATH1 data have a much larger overlap ( $64 \%$ of genes detected in either metaanalysis) and contain only 18 and $33 \%$ unique genes, respectively.
The mismatch between the results of the two microarray platforms is only to a small part due to a lacking overlap in the gene sets: $61 \%$ of the genes found regulated in the analysis of the Affymetrix data also have a probe on the CATMA array, and $90 \%$ of the genes found regulated on the CATMA array have a probe set on the Affymetrix array. The mismatch may rather demonstrate a weakness of quantitative hybridization-based methods, in which the sensitivity for detecting a given transcript is partly dependent on the sequence of the probe.

The outcome of this comparison demonstrates that the choice of technology is an important determinant of the final outcome of a large-scale transcriptomics experiment. Furthermore, it shows that the preselection of primary datasets for a meta-analysisreduction of the data to a set of comparable growth conditions, treatments, and time points (Brenner et al., 2012) vs. expansion to multiple conditions (Bhargava et al., 2013)—has only a relatively small impact on the outcome, at least in this particular case.

\section{DETERMINATION OF A CORE SET OF CYTOKININ-REGULATED TRANSCRIPTS}

Sixty five transcripts (12\% of all transcripts listed in the source datasets) were found to be induced in at least three of the four independent analyses (the area encircled with a black line in Figure 1B), and $23(3.6 \%)$ in all four. These transcripts can be referred to as the core set of cytokinin-induced transcripts. All transcripts that were positive in at least three of the four datasets shown in Figure $\mathbf{1}$ are listed in Table $\mathbf{2 A}$ which includes, in addition, also data from literature analyses. The entire list of cytokinin-induced transcripts alongside with information in which datasets they appear can be viewed in Supplementary Table $2 \mathrm{~A}$.

The list describing the advanced core set of cytokinininduced genes is with 65 members shorter than most other lists of cytokinin-induced genes in meta-analyses published here (Supplementary Tables 1,9) and in previous investigations (Brenner et al., 2012; Bhargava et al., 2013) or individual microarray studies referenced therein. This is due to the application of the most stringent selection criteria: Firstly, the high ratio of false-positive detection of individual microarray experiments was already reduced by combining several of these in the meta-analyses used as the basis for this study. Secondly, variation by technology (different microarray platforms and RNA sequencing, respectively) or different selection of original datasets for meta-analysis was eliminated by comparative overlap analysis represented as a Venn diagram in Figure 1. This way, the genes presented here-especially those found in all four source datasets-represent the most robust cytokinin response genes. A possible drawback of this stringent method is that genes, which are only present on one of the microarray platforms are wrongly eliminated as false negatives. This could particularly be the case for genes prone to high transcriptional variation due to signaling inputs other than cytokinin or for genes missing on one of the microarray platforms. However, notably a significant portion (57\%) of a list of 14 cytokinin marker genes (Nemhauser et al., 2006) are present in the advanced core set.

No common cytokinin-repressed transcripts were found in all four independent analyses. This was inevitable because in one 
Table 1 | Top 25 cytokinin-induced genes from a meta-analysis of transcriptomic data obtained with the CATMA microarray.

\begin{tabular}{|c|c|c|c|c|c|c|c|}
\hline CATMA ID & AGI & $\begin{array}{l}\text { Gene } \\
\text { symbol }\end{array}$ & Description & $\begin{array}{l}\text { Avg. ratio } \\
\text { BA15 vs. BA0 }\end{array}$ & $\begin{array}{l}\text { Avg. ratio } \\
\text { BA120 vs. BA0 }\end{array}$ & $\begin{array}{l}\text { Avg. ratio } \\
\text { BAx vs. BAO }\end{array}$ & $\begin{array}{c}\text { Meta } \\
\text { statistics }\end{array}$ \\
\hline CATMA5а58475 & AT5G62920 & $A R R 6$ & Type-A response regulator 6 & 4,83 & 3,08 & 3,96 & 129,82 \\
\hline CATMA4a31370 & AT4G29740 & $C K X 4$ & Cytokinin oxidase 4 & 7,60 & 6,29 & 6,95 & 86,41 \\
\hline CATMA1a18090 & AT1G19050 & $A R R 7$ & Type-A response regulator 7 & 11,72 & 8,94 & 10,33 & 85,09 \\
\hline CATMA5a43950 & AT5G47980 & & $\begin{array}{l}\text { HXXXD-type acyl-transferase family } \\
\text { protein }\end{array}$ & 2,00 & 12,29 & 7,15 & 80,18 \\
\hline CATMA1a57750 & AT1G68360 & & $\begin{array}{l}\mathrm{C} 2 \mathrm{H} 2 \text { and } \mathrm{C} 2 \mathrm{HC} \text { zinc fingers } \\
\text { superfamily protein }\end{array}$ & 3,02 & 2,51 & 2,77 & 77,01 \\
\hline CATMA5a17520 & AT5G19110 & & Aspartyl protease family protein & 2,01 & 4,48 & 3,25 & 76,89 \\
\hline CATMA2a38980 & AT2G40670 & ARR16 & Type-A response regulator 16 & 2,39 & 7,51 & 4,95 & 75,36 \\
\hline CATMA4a31320 & AT4G29690 & & $\begin{array}{l}\text { Alkaline-phosphatase-like family } \\
\text { protein }\end{array}$ & 2,10 & 6,76 & 4,43 & 67,16 \\
\hline CATMA2a00940 & AT2G01890 & PAP8 & Purple acid phosphatase 8 & 2,12 & 3,12 & 2,62 & 44,09 \\
\hline CATMA1a16200 & AT1G17190 & & Glutathione S-transferase tau 26 & 2,50 & 3,33 & 2,91 & 43,79 \\
\hline CATMA2a39655 & AT2G41310 & $A R R 8$ & Type-A response regulator 8 & 2,68 & 4,50 & 3,59 & 42,97 \\
\hline CATMA4a25920 & AT4G24190 & $S H D$ & HSP90-like protein SHEPERD & 2,08 & 2,91 & 2,50 & 39,78 \\
\hline CATMA1a41350 & AT1G50280 & & $\begin{array}{l}\text { Phototropic-responsive NPH3 family } \\
\text { protein }\end{array}$ & 5,76 & 9,11 & 7,44 & 39,67 \\
\hline CATMA1a44090 & AT1G53060 & & Legume lectin family protein & 2,12 & 16,16 & 9,14 & 34,57 \\
\hline CATMA1a26300 & AT1G28100 & & Unknown protein & 2,83 & 3,80 & 3,31 & 33,72 \\
\hline САТМАЗа52020 & AT3G58990 & $\mid P M / 1$ & Isopropylmalate isomerase 1 & 3,86 & 2,22 & 3,04 & 32,95 \\
\hline CATMA5a61570 & AT5G66210 & CPK28 & $\begin{array}{l}\text { Calcium-dependent protein kinase } \\
\text { family protein } 28\end{array}$ & 2,71 & 2,13 & 2,42 & 32,62 \\
\hline
\end{tabular}

The results of four different microarray studies (see Materials and Methods) were processed to calculate Meta statistics values using $R$ as described in Brenner et al. (2012). In all of these experiments, seedlings were grown for 5-7 days in liquid medium (1/2 MS, $1 \mathrm{~g} / \mathrm{L}$ sucrose, $0.5 \mathrm{~g} / \mathrm{L}$ MES, pH 5.7) before they were induced with 1 or $5 \mu \mathrm{M}$ of the synthetic cytokinin 6-benzyladenine (BA) for defined time periods. The labels BAO, BA15, BA120 correspond to 0,15 or 120 min of induction, respectively. This table shows the top 25 genes of Supplementary Table 1E; the complete result can be viewed in Supplementary Table 1.

of the meta-analyses no gene was found that matched the cutoff of an average fold-change $=0.5$ (Brenner et al., 2012). But surprisingly, there were also no cytokinin-repressed transcripts consistently found in all three remaining analyses. Therefore, we assembled all transcripts found in only two independent analyses as cytokinin-repressed transcripts (the area encircled with a black line in Figure 1B) in Table 2B. The entire list of cytokinin-repressed transcripts alongside with information in which datasets they appear can be viewed in Supplementary Table 2B. Because these genes were less well supported than the cytokinin-induced genes we focused for the following analyses only on the latter category.

\section{COMPARISONS OF CYTOKININ-INDUCED ARABIDOPSIS GENES WITH THEIR RICE ORTHOLOGS}

We made an attempt to find evolutionary conserved cytokinininduced genes by analyzing the cytokinin response of rice orthologs of regulated Arabidopsis genes in the available transcriptomic data from rice. Only two suitable datasets from rice could be used for this analysis, therefore the rice data lack the breadth sufficient to conduct a meaningful meta-analysis. For this reason, we made a direct comparison with these two datasets.

For 40 of the 65 cytokinin-induced Arabidopsis genes (62.5\%) at least one rice ortholog was identified (Supplementary Table 3). 17 of these genes $(42.5 \%)$ have at least one rice ortholog that is also induced by cytokinin. Besides genes of the cytokinin metabolism and signaling circuitry, such as those encoding typeA response regulators, cytokinin receptors, and enzymes involved in cytokinin metabolism, several other orthologous genes with other interesting functions are also induced by cytokinin in rice. ACR4, EXPA1, and AMP1 are discussed in more detail further below. Other genes include CYP87A2, encoding a cytochrome P450 with unknown function, the purple acid phosphatase gene PAP8, PILS5 encoding a member of a recently characterized novel 


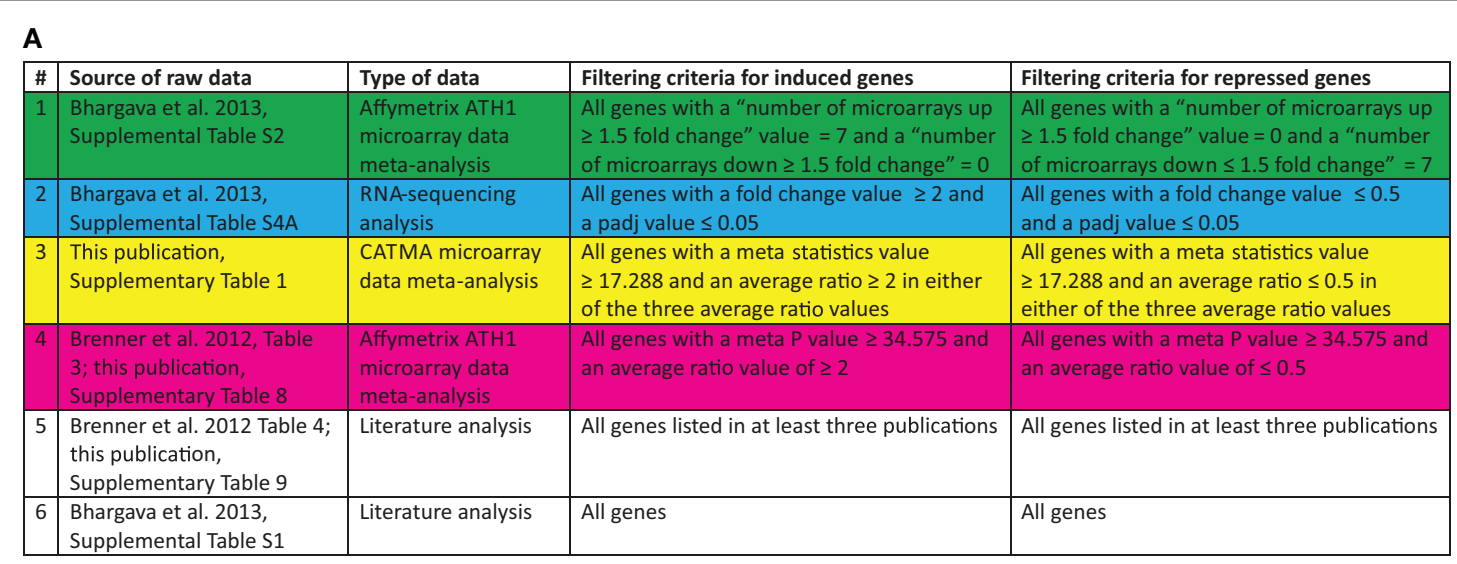

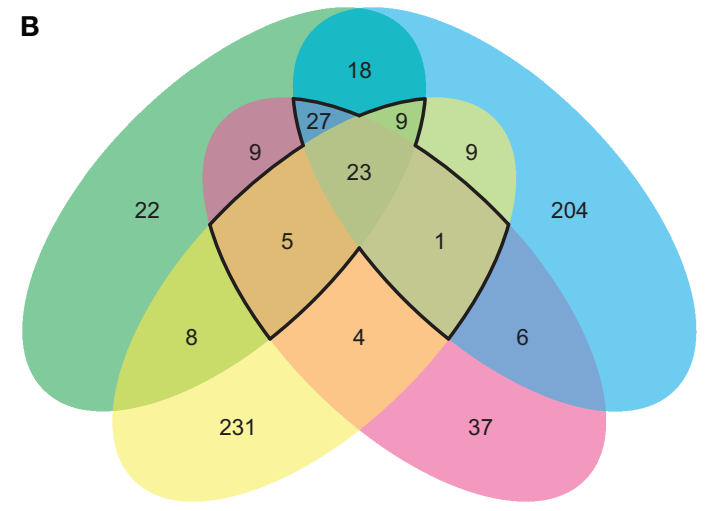

FIGURE 1 | Data sources and Venn diagram summarizing large-scale transcriptomic studies related to cytokinin. (A) Source and type of data reporting cytokinin-regulated gene expression used in this study. Overlap analysis of cytokinin-induced (B) and

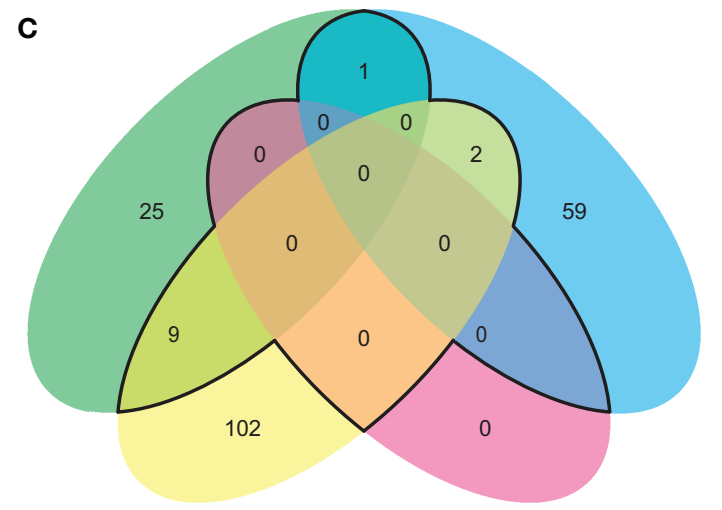

cytokinin-repressed (C) genes identified in the different studies. The color code of the circles in $\mathbf{( B , C )}$ corresponds to the code in the table shown in (A). The core sets of regulated genes are encircled with a black line. auxin efflux carrier protein family (Barbez et al., 2012; Dal Bosco et al., 2012; Feraru et al., 2012), a flavonoid sulfotransferase gene (SULTR202B1) (Hashiguchi et al., 2013), the aquaporin gene NLM1, the glutaredoxin gene ROXY2, a gene encoding a cytochrome $\mathrm{P} 450$ enzyme required in the sporophytic tissue of the mother plant to promote seed growth (EOD3) (Fang et al., 2012), and the gene encoding the marneral oxidase MRO. The evolutionary conserved induction of these genes by cytokinin in both distantly related species suggests a functional relevance of this regulation. We anticipate that analysis of the transcriptomic response to cytokinin in rice covering more tissues, developmental stages and time points would reveal additional orthologous genes regulated by cytokinin which went undiscovered in the limited data set currently available.

\section{FUNCTIONS OF THE CORE SET OF CYTOKININ-REGULATED TRANSCRIPTS}

To get a first insight into the functions of the core set of cytokininregulated transcripts, we carried out a rough functional categorization of the genes, using the GO functional categorization tool at TAIR, which uses a set of less specialized GO terms (GOslim). Remarkably, the molecular functions and biological roles of more than half of the cytokinin-regulated genes do not belong to one of the major categories (Figure 2). The three major categories of molecular functions were transferase, protein binding and hydrolase activity. Relatively few genes are candidates for downstream signaling processes (transcription factors, protein-modifying or degradation processes). The majority of the genes characterized to be involved in a biological process play a role in developmental processes, responses to stress, signal transduction, and responses to abiotic and biotic stimuli, consistent with previous knowledge about cytokinin action (Werner and Schmülling, 2009; Kieber and Schaller, 2014).

To investigate the functional categories of cytokinin-induced genes in more detail, we carried out a statistical analysis of the abundance of the GO terms associated with the corresponding genes using AmiGO (Carbon et al., 2009) (Supplementary Figure 1 and Supplementary Table 4). Unsurprisingly, GO categories associated with hormone-in particular cytokininaction and metabolism were most strongly enriched among the cytokinin-induced transcripts. Other notable overrepresented GO terms are associated with circadian rhythm, flavonoid-in particular anthocyanin-metabolism, and thalianol metabolism. Additionally, a substantial fraction of the encoded proteins have glutaredoxin/arsenate reductase activity. Due to the small number of cytokinin-repressed transcripts, the GO term enrichment 
Table 2 | Advanced core set of cytokinin-regulated genes.

(A) Genes induced by cytokinin treatment and found in at least three of four data sources. The rice orthologs of the Arabidopsis genes listed in this table were also checked for cytokinin induction. The results of this analysis is presented in the last two columns. NA, not applicable.

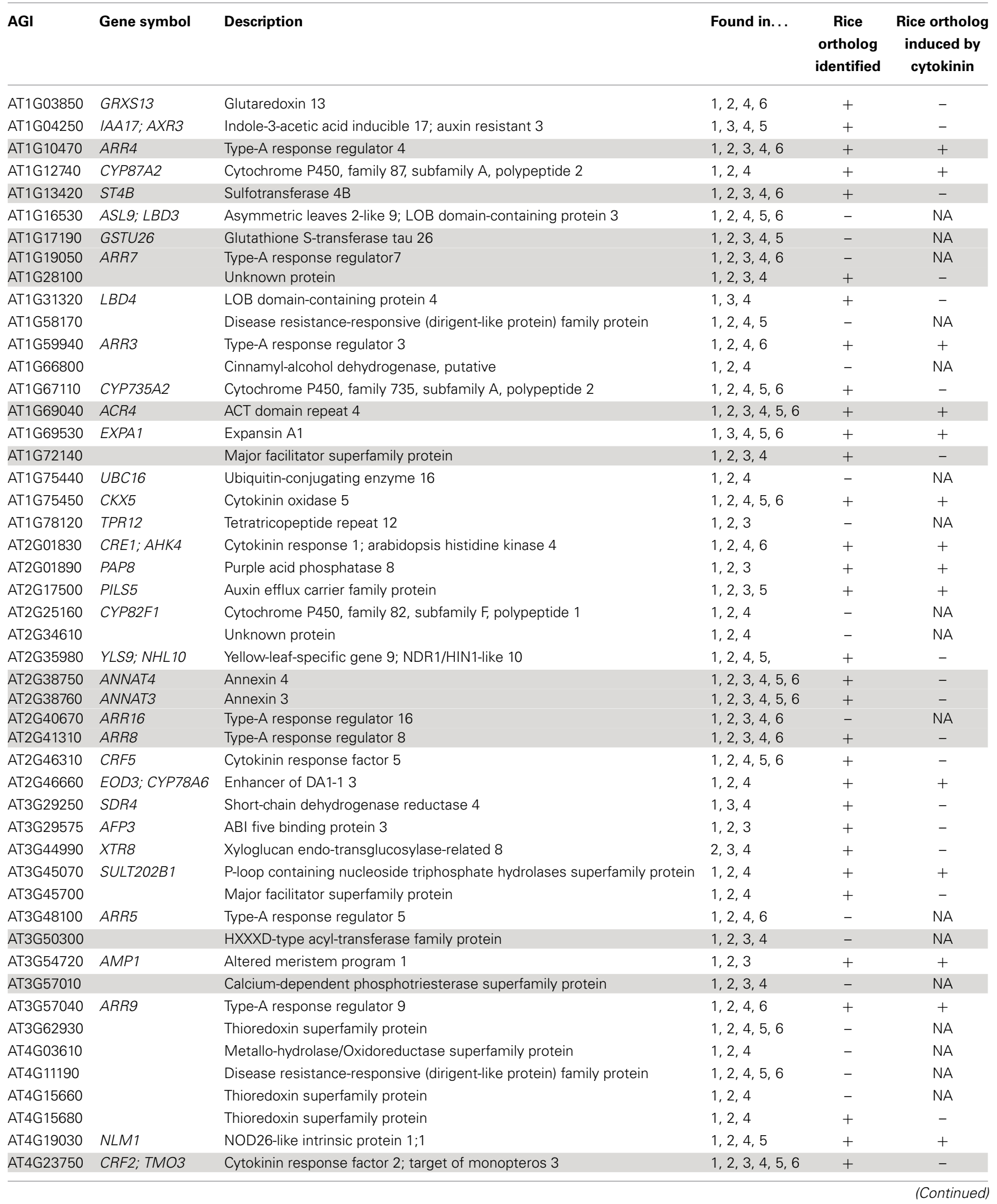


Table 2 | Continued

\begin{tabular}{|c|c|c|c|c|c|}
\hline AGI & Gene symbol & Description & Found in... & $\begin{array}{c}\text { Rice } \\
\text { ortholog } \\
\text { identified }\end{array}$ & $\begin{array}{l}\text { Rice ortholog } \\
\text { induced by } \\
\text { cytokinin }\end{array}$ \\
\hline AT4G29690 & & Alkaline-phosphatase-like family protein & $1,2,3,4$ & + & - \\
\hline AT4G29700 & & Alkaline-phosphatase-like family protein & $1,3,4$ & + & - \\
\hline AT4G29740 & $C K X 4$ & Cytokinin oxidase 4 & $1,2,3,4,5,6$ & + & - \\
\hline AT5G05860 & UGT76C2 & UDP-glucosyl transferase $76 \mathrm{C} 2$, cytokinin N-glucosyltransferase & $1,2,3,4,5$ & + & - \\
\hline AT5G14070 & ROXY2 & Glutaredoxin ROXY2 & $1,2,4$ & + & + \\
\hline AT5G19110 & & Eukaryotic aspartyl protease family protein & $1,2,3$ & - & NA \\
\hline AT5G19260 & FAF3 & Fantastic four 3 & $1,2,3,4$ & + & - \\
\hline AT5G26260 & & TRAF-like family protein & $1,2,4$ & - & NA \\
\hline AT5G42590 & MRO; CYP71A16 & Marneral oxidase & $1,2,3,4$ & + & + \\
\hline AT5G47950 & & HXXXD-type acyl-transferase family protein & $1,2,3,4$ & - & NA \\
\hline AT5G47980 & & HXXXD-type acyl-transferase family protein & $1,2,3,4$ & - & NA \\
\hline AT5G47990 & THAD; CYP705A5 & Thalian-diol desaturase & $1,2,4,5$ & - & NA \\
\hline AT5G48000 & THAH; CYP708A2 & Thalianol hydroxylase & $1,2,3,4,5$ & - & NA \\
\hline AT5G48010 & THAS & Thalianol synthase & $1,2,4,5$ & - & NA \\
\hline AT5G60890 & ATR1; MYB34 & Altered tryptophan regulation 1; MYB domain protein 34 & $1,2,3,5$ & - & NA \\
\hline AT5G62920 & $A R R 6$ & Type-A response regulator 6 & $1,2,3,4,6$ & + & + \\
\hline
\end{tabular}

(B) Genes repressed by cytokinin treatment and found in at least two of four data sources.

\begin{tabular}{|c|c|c|c|}
\hline AGI & Gene symbol & Short description & Found in ... \\
\hline AT2G28120 & & Major facilitator superfamily protein & 1,3 \\
\hline AT2G35270 & GIK & Giant killer GIK & $1,3,6$ \\
\hline AT2G44500 & & O-fucosyltransferase family protein & 1,3 \\
\hline AT3G01190 & & Peroxidase superfamily protein & $1,3,6$ \\
\hline AT3G11340 & UGT76B1 & UDP-dependent glycosyltransferase 76B1 & 1,3 \\
\hline AT3G13760 & & Cysteine/Histidine-rich $\mathrm{C} 1$ domain family protein & 1,3 \\
\hline AT4G14130 & XTH15; XTR7 & Xyloglucan endotransglycosylase/hydrolase 15; xyloglucan endotransglycosylase 7 & 1,3 \\
\hline AT5G01210 & & HXXXD-type acyl-transferase family protein; & 2,3 \\
\hline AT5G01740 & & Nuclear transport factor 2 (NTF2) family protein & 1,2 \\
\hline AT5G09440 & EXL4 & Exordium like 4 & 1,3 \\
\hline AT5G10580 & & Protein of unknown function, DUF599; & 1,3 \\
\hline AT5G57685 & GDU3 & Glutamine dumper 3 & 2,3 \\
\hline
\end{tabular}

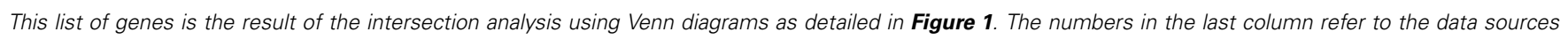

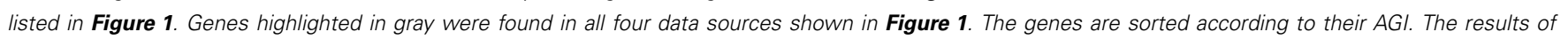
literature analyses (no. 5 and 6) have been included in the table as additional information.

analysis did not return any useful results for downregulated genes (data not shown).

For more than two thirds of the core set of cytokinin-induced genes (Table 2) - $40 \%$ of the genes detected in at least three largescale analyses and $35 \%$ of the 23 genes detected in all four data sources-no published data regarding their functional characterization exist. A notable group among these consists of three genes encoding HXXXD-type acyl transferases, two of which are closely related; the third one is encoded on the same operon-like mRNA as the cytokinin-regulated genes encoding three thalianol metabolic enzymes THAS, THAD, and THAH (Brenner et al., 2012). Also, there are two closely related (and genomically neighboring) genes encoding alkaline phosphatase-like family proteins, which have thus far not been studied. The same is true for three thioredoxin genes. These genes are prime candidates to investigate in order to unravel so far unknown connections between the immediate early cytokinin signaling chain and gene expression on the one hand and the pleiotropic physiological and phenotypical output on the other hand.

The roles of many of the already functionally characterized genes were discussed in previous articles (Brenner et al., 2005, 2012; Brenner and Schmülling, 2012; Bhargava et al., 2013; Ramireddy et al., 2013), such as auxin- and redox-related genes as well as genes involved in cytokinin signaling and homeostasis. Other genes with known function, however, were not discussed in detail. In the following sections we present and discuss a few of these as they might indicate underexplored areas of cytokinin research. 


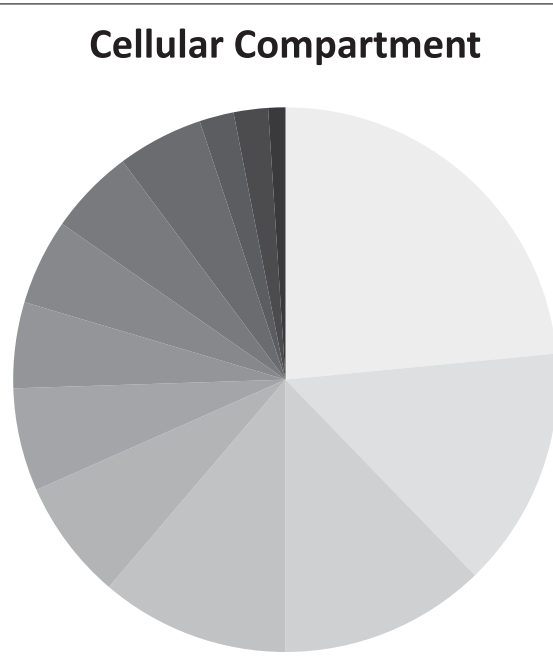

\section{Molecular Function}

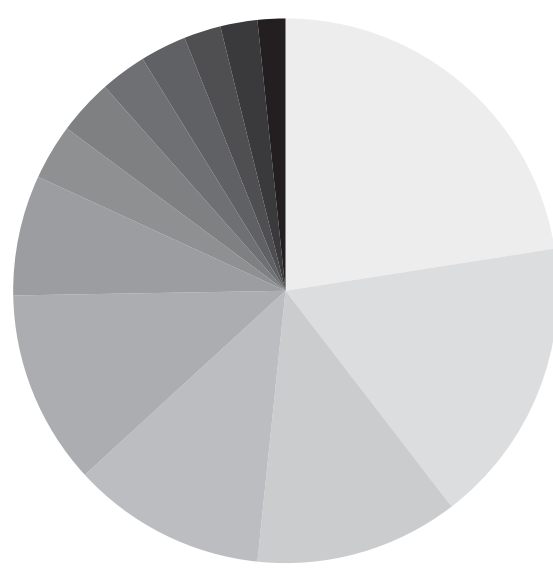

Biological Process

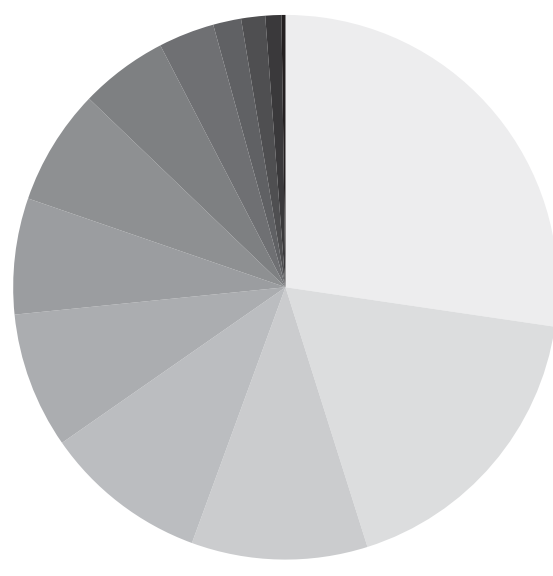

\section{\% Category}

\section{4 nucleus}

15 other cytoplasmic components

\section{2 extracellular}

11 chloroplast

7 other membranes

6 other intracellular components

$5 \mathrm{ER}$

5 other cellular components

5 plasma membrane

5 mitochondria

2 cell wall

2 unknown cellular components

1 cytosol

\section{2 other enzyme activity}

17 other binding

12 other molecular functions

12 transferase activity

12 protein binding

7 hydrolase activity

3 unknown molecular functions

3 transporter activity

3 nucleotide binding

3 kinase activity

2 transcription factor activity

2 receptor binding or activity

2DNA or RNA binding

27 other cellular processes

18 other metabolic processes

11 other biological processes

10 developmental processes

8 response to stress

7 signal transduction

7 response to abiotic or biotic stimulus

3 transport

3 transcription,DNA-dependent

2 protein metabolism

1 unknown biological processes

- 1 cell organization and biogenesis

<1DNA or RNA metabolism
FIGURE 2 | Annotated subcellular localizations, molecular functions and biological processes of the core set of cytokinin-induced genes. The genes listed in Table 2A were evaluated with regard to their GO categorization using the GO categorization tool provided by TAIR (http://www.arabidopsis. org/tools/bulk/go/index.jsp), which matches a given set of genes with a reduced set of basic GO terms (GOslim). The resulting table was imported into Microsoft Excel for generating the cake diagrams. The Excel diagrams were reformatted using CoreIDRAW to fit them into the frame of a figure. 
One remarkable group of genes is represented by expansin A1 (EXPA1): A conspicuous number of expansin genes is regulated by cytokinin in individual experiments (data not shown), but only expansin A1 is consistently upregulated throughout all of them. Expansins, encoded by a family of at least 36 genes in Arabidopsis (Sampedro et al., 2006), are proteins capable of loosening the cell wall in a $\mathrm{pH}$-dependent manner without having to cleave covalent molecular bounds (Cosgrove, 2000; Durachko and Cosgrove, 2009), probably by enabling slippage between cellulose microfibrils and matrix glucans under acidic conditions (Wei et al., 2011). Therefore, they are thought to be the major players in short-term cell wall loosening (Cosgrove, 1999) excerting functions in cell growth or differentiation processes. Another cytokinin-induced gene coding for a cell-wall modifying enzyme, a xyloglucan endo-transglucosylase, is encoded by XTR8. Since cytokinin is involved in regulating growth processes and growth involves the irreversible increase of the individual cell volume requiring plastic stretching of the cell wall, it would be worth investigating whether at least part of the cytokinin-mediated growth response is mediated by modulation of expansin gene expression.

Two of the 17 known sulfotransferase genes in Arabidopsis (Klein and Papenbrock, 2004) are induced by cytokinin, ST4B and SULT201B1. The latter sulfotransferase acts on flavonoid glucosides (Hashiguchi et al., 2013), while the substrate of the former sulfotransferase is not known. Flavonoids are inhibitors of basipetal auxin transport in roots (Brown et al., 2001). As it is thought generally that sulfatation modulates the biological activity of compounds by increasing their water solubility (Hashiguchi et al., 2013) it is tempting to speculate that cytokinin could act indirectly on polar auxin transport by modification of the biological activity of flavonoids through modulation of sulfotransferase activity.

Annexins are a family of $\mathrm{Ca}^{2+}$-binding membrane-binding proteins present in all kingdoms of life (Rescher and Gerke, 2004). Plant annexins exhibit diverse activities, such as hydrolyzing ATP and GTP, forming $\mathrm{Ca}^{2+}$ channels, acting as peroxidases, or binding to F-actin (Mortimer et al., 2008). The cytokinin-regulated ANNAT3 gene is also induced by $\mathrm{H}_{2} \mathrm{O}_{2}$ and ANNAT3 interacts with ANNAT1, a regulator of the $\mathrm{H}_{2} \mathrm{O}_{2}$-induced $\mathrm{Ca}^{2+}$ signal in Arabidopsis roots (Richards et al., 2014). ANNAT4 also interacts with ANNAT1 and plays a role in salt and drought stress adaptation (Huh et al., 2010).

Another remarkable cytokinin-induced gene is $A M P 1$. The amp1 mutant shows high cytokinin levels, altered embryonic patterning, faster vegetative growth, constitutive photomorphogenesis and precocious flowering (Chaudhury et al., 1993). The increased level of cytokinin corresponds with the de-etiolation response shown by amp1 (Chin-Atkins et al., 1996) and is due to increased synthesis, not to decreased degradation, suggesting that AMP1 is a negative regulator of cytokinin synthesis (Nogué et al., 2000). AMP1 encodes a putative carboxypeptidase with high similarity to $\mathrm{N}$-acetyl $\alpha$-linked acidic dipeptidases, suggesting that its product modulates the level of a small signaling molecule (Helliwell et al., 2001). AMP1 interferes with auxin activity in meristem control, where $A M P 1$ acts as a differentiationpromoting agent (Vidaurre et al., 2007). However, the functional relevance of the mutual regulatory feedback between $A M P 1$ activity and cytokinin biosynthesis and its link to auxin action in regulating meristem activity awaits further analysis.

It is long known that the abundance of the ACR4 transcript is increased in response to cytokinin (Hsieh and Goodman, 2002). The ACR domain, of which ACR4 (and the other plant ACR proteins) possess four repeats, serves in bacteria as an amino acid binding domain accomplishing allosteric regulation of the enzymatic activity of the protein in which it is located (Schuller et al., 1995; Grant et al., 2001). Unlike the bacterial proteins, plant ACR proteins have no known enzymatic domain and are probably pure receptors and/or signal transducers (Hsieh and Goodman, 2002). The only functional information comes from rice, where an ACR protein binds to a nuclear chaperone, but the meaning of this interaction is not understood (Hayakawa et al., 2006).

\section{PROMOTERS OF CYTOKININ-INDUCED GENES}

Several investigations on the properties of cytokinin-regulated promoters have been made. Generally, it is an accepted model that type-B ARR proteins bind to specific cis-elements in the promoters of cytokinin-induced genes to activate their transcripton. It has been demonstrated that a pentanucleotide motif with the sequence AGAT[T,C] (cytokinin response motif, CRM) (Sakai et al., 2000; Hosoda et al., 2002; Imamura et al., 2003) is sufficient to bind type-B ARR proteins, and that ARR1 in particular binds to the octameric sequence AAGAT[T,C]TT (extended cytokinin response motif, ECRM) (Sakai et al., 2001; Taniguchi et al., 2007). The latter motif was shown to exhibit cis-regulatory activity in planta (Ramireddy et al., 2013).

Taking advantage of the very low probability of false positive genes, we investigated the occurrence, frequency, and distribution of these two motifs in the promoters of the core set of 65 cytokinin-induced genes from Table 2A (Supplementary Figure 2 ). Comparison with a set of 103 promoters of genes not regulated by cytokinin (listed in Supplementary Table 5) showed that the CRM is not overrepresented in cytokinin-responsive promoters. In contrast, the ECRM is significantly overrepresented about 2 -fold in cytokinin-inducible promoters. However, it is missing in 36 of the 65 promoters (55\%), among them those of several wellknown immediate-early cytokinin response genes (e.g., CKX4, CRF2, CRF5, see Supplementary Figure 2). Consistent with earlier observations (Brenner et al., 2012), there must be other motifs that mediate cytokinin responsiveness. These could be other type$B$ response regulator binding sites, but also binding sites for the CRFs. Alternatively, there could be functionally relevant ECRMs outside the analyzed -1000 bp region, but these cases appear not to be very frequent (Franco-Zorrilla et al., 2014).

It could be that other type-B ARRs than ARR1 bind preferentially to different ECRM variants. It was indeed found that type-B response regulators belonging to different evolutionary lineages in Arabidopsis and rice have a differing capability to activate the Arabidopsis ARR6 promoter (Kim et al., 2012; Ramireddy et al., 2013). On the other hand, our own bioinformatical analysis similar to that carried out to find the ECRM (Taniguchi et al., 2007) did not result in ECRM variants other than the known ARR1binding AAGAT[T,C]TT motif (data not shown). In summary, we can conclude that neither is the presence of a certain frequency 
of CRMs diagnostic for a cytokinin-inducible promoter, nor does the absence of an ECRM exclude the cytokinin responsiveness of a promoter. Hence, a clear sequence motif-based definition of a cytokinin-inducible promoter is still missing.

Recently, highly degenerated novel binding motifs for the typeB ARRs ARR11 and ARR14 were identified using protein-binding microarrays containing oligonucleotide probes (Franco-Zorrilla et al., 2014). From these motifs we obtained the consensus sequence $[\mathrm{ACT}][\mathrm{AG}][\mathrm{GT}] \mathrm{AT}[\mathrm{ACT}][\mathrm{CT}][\mathrm{ACGT}]$. We tested whether any single motif that can be derived from this consensus is enriched in cytokinin-responsive promoters. In addition to the ARR1 binding site, the ECRM AAGAT[TC]TT (Taniguchi et al., 2007; Bhargava et al., 2013), we found five more octameric sequence motifs enriched in cytokinin-responsive promoters: CATATATA, TATATATA, TATATTCC, TATATTTA, and TGTATTTC, albeit some with a $p$-value between 0.05 and 0.06 (Figure 3A, Supplementary Table 6).

To take this approach further, we reasoned that the central AT present in all motifs could be the only conserved sequence required for binding of this class of transcription factors. Therefore, we investigated whether any possible octamer

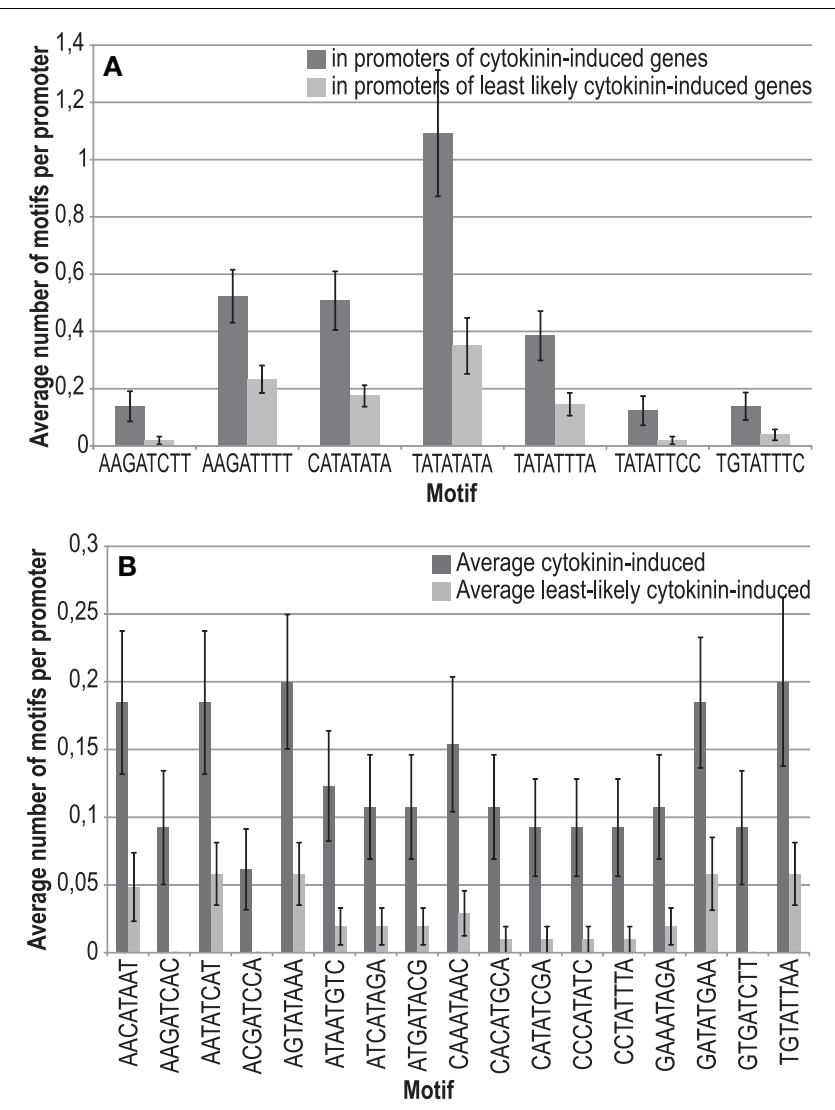

FIGURE 3 | Sequences and frequencies of novel potential type-B response regulator binding sites that were enriched in promoters of cytokinin-responsive genes in comparison to a control set of promoters. (A) Enriched motifs derived from the consensus sequence (ACT)(AG)(GT)AT(ACT)(CT)(ACGT), characterized as binding motif for the type-B ARRs ARR11 and ARR14 (Franco-Zorrilla et al., 2014). (B) Enriched motifs derived from all possible DNA octamers containing a central AT. containing a central AT is overrepresented in cytokininresponsive promoters. In this analysis, we found 17 motifs, which are significantly overrepresented 2-fold or more (Figure 3B, Supplementary Table 7). Notably, the more frequent variant of the ARR1 binding motif (AAGATTTT) is not among the motifs that matched the criteria of a 2 -fold enrichment for this most exhaustive analysis, having an enrichment of only 1.4-fold.

Combining the two analyses described before (Supplementary Tables 6,7$)$ revealed that all but one of the promoters of the advanced core set of cytokinin-responsive genes contains at least one of the motifs identified, and that, in total, these motifs are enriched almost 3.5-fold in comparison to a set of least likely cytokinin-regulated promoters (Supplementary Table 8). Figure 4 shows a sequence logo, which indicates the frequencies of the bases in the hypothetical cytokinin-responsive DNA element derived from this analysis. Evidently, this result is derived from a purely bioinformatical approach and needs experimental verification. However, this sequence model seems to be typical for type-B response regulators: All type-B response regulator binding sites characterized so far are AT-rich sequence motifs (Sakai et al., 2000, 2001; Hosoda et al., 2002; Imamura et al., 2003; Taniguchi et al., 2007; Franco-Zorrilla et al., 2014). By contrast, the typical sequence motifs for ERF/AP2 transcription factors, to which the CRFs belong, are GC-rich (Franco-Zorrilla et al., 2014).

Recently, an analysis of the cis elements bound by 24 different transcription families was published (Franco-Zorrilla et al., 2014). Motifs with similar properties as the novel candidate motifs proposed here, such as an AT in the center of the octamer, were found for MYB-related and MYB GARP-G2 transcription factors, both of which belong to the same superfamily of MYB transcription factors as the type-B response regulators, as well as for the C2C2 GATA-type protein GATA12. The flanking sequences of these motifs, however, differ from the ones of the candidate motifs proposed in Figure 3. Other transcription factor families binding to AT-rich sequence motifs are HD-ZIP proteins, $\mathrm{C} 2 \mathrm{C} 2 \mathrm{YABBY}$ factors, and AHL proteins. The latter class binds to sequences containing no $\mathrm{G}$ or $\mathrm{C}$ at all. Apart from the motif ATATATAT for AHL12, none of the motifs identified by FrancoZorrilla et al. (2014) is highly similar to the candidate motifs proposed in this work.

\section{CONCLUSION}

Ten years of large-scale transcriptomics in the cytokinin field have yielded a sufficient amount of data to identify a core set

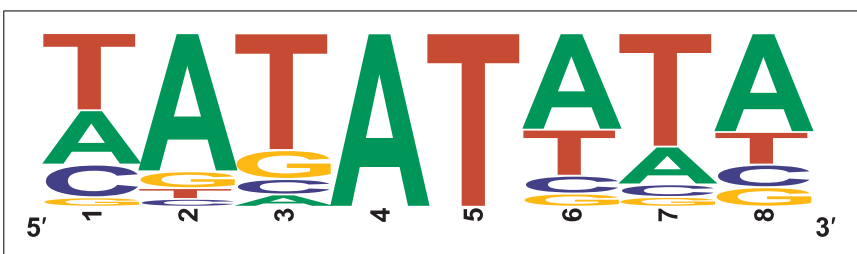

FIGURE 4 | Sequence logo of a novel model of a potential type-B response regulator binding site. The motif combines all single motifs found in the analyses pictured in Figures 3A,B and shows the frequencies of the bases at the respective position in all promoters of the 65 cytokinin-regulated genes shown in Table $\mathbf{2 A}$. 
of cytokinin-responsive genes. A large portion of the cytokinininduced genes function in and around cytokinin signaling and metabolism. Of the remaining genes, there are several characterized examples encoding proteins with the potential of directly mediating cytokinin action, such as expansins, or the promoter of cell differentiation AMP1. The potential function of other genes, such as annexin genes, ACR4, or ATR1, in mediating cytokinin action is more enigmatic. Surprisingly, there are no consistently cytokinin-repressed genes. This may be partly due to the poor performance of microarrays in detecting low expression levels with little noise, which compromises reliable detection of downregulation.

One aspect of gene regulation that is missing from this analysis is the regulation of microRNAs. This important regulatory mechanism for decreasing gene activity is inevitably absent in this type of analysis because microRNAs are not represented on the microarrays considered here. The only information comes from the RNA sequencing analysis data (Bhargava et al., 2013), where among six non-protein coding genes two microRNAs were found to be regulated (miR163 and miR414), the former having a known target gene (AT1G15125, encoding a S-adenosyl-l-Metdependent methyltransferase) whose transcript was consequently decreased. Unfortunately, the analysis presented here is lacking useful information on cytokinin-repressed transcripts, so a reverse search for potential microRNAs targeting these genes cannot be carried out.

Given the fact that in most cases the binding motifs for transcription factors are clearly and significantly overrepresented in their target promoters, the search for enriched motifs is an accepted way to identify new potential binding motifs in the promoters of a set of co-regulated genes. However, it was shown that the experimentally identified binding motifs of the typeB response regulators ARR11 and ARR14 are surprisingly not overrepresented in the promoters of cytokinin-regulated genes (Franco-Zorrilla et al., 2014), which may raise concerns whether this approach is appropriate in the case of cytokinin-regulated promoters. At this point, it should be noted that ARR11 and ARR14 are not considered to be the most important transcription factors for mediating cytokinin action. Thus, it may well be possible that the respective binding sites for the major type- $\mathrm{B}$ response regulators ARR1, ARR10, and ARR12 (Mason et al., 2005; Argyros et al., 2008; Ishida et al., 2008) may indeed be enriched in cytokinin-responsive promoters, and for the characterized binding motif of ARR1, the ECRM, this is a true fact (Supplementary Figure 2). For that reason, we are convinced that the overrepresentation analysis carried out here is a valid approach also in the case of the cytokinin signaling system. Our bioinformatic approaches to find alternative binding motifs using either degenerated motifs coming from an in vitro experiment or a randomly degenerated set of octamers has led to the identification of a number of enriched sequence motifs in cytokinin-responsive promoters. The AT-rich consensus of the motifs is consistent with the previously identified nature of type-B response regulator binding elements. As our analysis is pure bioinformatics, the true binding capacity of type- $\mathrm{B}$ response regulators to the novel candidate sequence motifs must ultimately be determined experimentally.

\section{AUTHOR CONTRIBUTIONS}

Wolfram G. Brenner designed and carried out the research, evaluated the results, and contributed to writing the manuscript. Thomas Schmülling contributed to evaluating the results and writing the manuscript. Both authors finally approved the manuscript.

\section{ACKNOWLEDGMENTS}

This work has been supported by a grant of Deutsche Forschungsgemeinschaft (DFG) in the frame of SFB 973 and by the Dahlem Centre of Plant Sciences (DCPS). The authors thank Dr. Alexander Heyl for advice regarding the identification of orthologous genes.

\section{SUPPLEMENTARY MATERIAL}

The Supplementary Material for this article can be found online at: http://www.frontiersin.org/journal/10.3389/fpls.2015.00029/ abstract

\section{REFERENCES}

Aerts, S., Thijs, G., Coessens, B., Staes, M., Moreau, Y., and Moor, B. D. (2003). Toucan: deciphering the cis-regulatory logic of coregulated genes. Nucleic Acids Res. 31, 1753-1764. doi: 10.1093/nar/gkg268

Aerts, S., Van Loo, P., Thijs, G., Mayer, H., De Martin, R., Moreau, Y., et al. (2005) TOUCAN 2: the all-inclusive open source workbench for regulatory sequence analysis. Nucleic Acids Res. 33, W393-W396. doi: 10.1093/nar/gki354

Allemeersch, J., Durinck, S., Vanderhaeghen, R., Alard, P., Maes, R., Seeuws, K., et al. (2005). Benchmarking the CATMA microarray. A novel tool for Arabidopsis transcriptome analysis. Plant Physiol. 137, 588-601. doi: 10.1104/pp.104.051300

Argyros, R. D., Mathews, D. E., Chiang, Y.-H., Palmer, C. M., Thibault, D. M., Etheridge, N., et al. (2008). Type B response regulators of Arabidopsis play key roles in cytokinin signaling and plant development. Plant Cell 20, 2102-2116. doi: 10.1105/tpc.108.059584

Barbez, E., Kubes, M., Rolcik, J., Beziat, C., Pencik, A., Wang, B., et al. (2012). A novel putative auxin carrier family regulates intracellular auxin homeostasis in plants. Nature 485, 119-122. doi: 10.1038/nature11001

Benjamini, Y., and Hochberg, Y. (1995). Controlling the false discovery rate-a practical and powerful approach to multiple testing. J. R. Stat. Soc. B Methods 9, 289-300.

Bhargava, A., Clabaugh, I., To, J. P., Maxwell, B. B., Chiang, Y. H., Schaller, G. E., et al. (2013). Identification of cytokinin-responsive genes using microarray meta-analysis and RNA-Seq in Arabidopsis. Plant Physiol. 162, 272-294. doi: 10.1104/pp.113.217026

Brenner, W. G., Ramireddy, E., Heyl, A., and Schmülling, T. (2012). Gene regulation by cytokinin. Front. Plant Sci. 3:8. doi: 10.3389/fpls.2012.00008

Brenner, W. G., Romanov, G. A., Köllmer, I., Bürkle, L., and Schmülling, T. (2005). Immediate-early and delayed cytokinin response genes of Arabidopsis thaliana identified by genome-wide expression profiling reveal novel cytokinin-sensitive processes and suggest cytokinin action through transcriptional cascades. Plant J. 44, 314-333. doi: 10.1111/j.1365-313X.2005.02530.x

Brenner, W., and Schmülling, T. (2012). Transcript profiling of cytokinin action in Arabidopsis roots and shoots discovers largely similar but also organ-specific responses. BMC Plant Biol. 12:112. doi: 10.1186/1471-2229-12-112

Brown, D. E., Rashotte, A. M., Murphy, A. S., Normanly, J., Tague, B. W., Peer, W. A., et al. (2001). Flavonoids act as negative regulators of auxin transport in vivo in Arabidopsis. Plant Physiol. 126, 524-535. doi: 10.1104/pp. 126.2.524

Carbon, S., Ireland, A., Mungall, C. J., Shu, S., Marshall, B., Lewis, S., et al. (2009). AmiGO: online access to ontology and annotation data. Bioinformatics 25, 288-289. doi: 10.1093/bioinformatics/btn615

Chaudhury, A. M., Letham, S., Craig, S., and Dennis, E. S. (1993). ampl-a mutant with high cytokinin levels and altered embryonic pattern, faster vegetative growth, constitutive photomorphogenesis and precocious flowering. Plant J. 4, 907-916. doi: 10.1046/j.1365-313X.1993.04060907.x 
Che, P., Gingerich, D. J., Lall, S., and Howell, S. H. (2002). Global and hormoneinduced gene expression changes during shoot development in Arabidopsis. Plant Cell 14, 2771-2785. doi: 10.1105/tpc.006668

Chin-Atkins, A., Craig, S., Hocart, C., Dennis, E., and Chaudhury, A. (1996). Increased endogenous cytokinin in the Arabidopsis ampl mutant corresponds with de-etiolation responses. Planta 198, 549-556. doi: 10.1007/bf00262641

Cosgrove, D. J. (1999). Enzymes and other agents that enhance cell wall extensibility. Annu. Rev. Plant Physiol. Plant Mol. Biol. 50, 391-417. doi: 10.1146/annurev.arplant.50.1.391

Cosgrove, D. J. (2000). Loosening of plant cell walls by expansins. Nature 407, 321-326. doi: 10.1038/35030000

Crooks, G. E., Hon, G., Chandonia, J.-M., and Brenner, S. E. (2004). WebLogo: a sequence logo generator. Genome Res. 14, 1188-1190. doi: 10.1101/gr.849004

Crowe, M. L., Serizet, C., Thareau, V., Aubourg, S., Rouze, P., Hilson, P., et al. (2003). CATMA: a complete Arabidopsis GST database. Nucleic Acids Res. 31, 156-158. doi: 10.1093/nar/gkg071

Dal Bosco, C., Dovzhenko, A., and Palme, K. (2012). Intracellular auxin transport in pollen. Plant Signal. Behav. 7, 1504-1505. doi: 10.4161/psb.21953

De Magalhães, J. P., Curado, J., and Church, G. M. (2009). Meta-analysis of age-related gene expression profiles identifies common signatures of aging. Bioinformatics 25, 875-881. doi: 10.1093/bioinformatics/btp073

Durachko, D. M., and Cosgrove, D. J. (2009). Measuring plant cell wall extension (creep) induced by acidic $\mathrm{pH}$ and by alpha-expansin. J. Vis. Exp. Available online at: http://www.jove.com/video/1263 [Accessed 03/11/2009].

Fang, W., Wang, Z., Cui, R., Li, J., and Li, Y. (2012). Maternal control of seed size by EOD3/CYP78A6 in Arabidopsis thaliana. Plant J. 70, 929-939. doi: 10.1111/j.1365-313X.2012.04907.x

Feraru, E., Vosolsobě, S., Feraru, M. I., Petrášek, J., and Kleine-Vehn, J. (2012). Evolution and structural diversification of PILS putative auxin carriers in plants. Front. Plant Sci. 3:227. doi: 10.3389/fpls.2012.00227

Franco-Zorrilla, J. M., López-Vidriero, I., Carrasco, J. L., Godoy, M., Vera, P., and Solano, R. (2014). DNA-binding specificities of plant transcription factors and their potential to define target genes. Proc. Natl. Acad. Sci. U.S.A. 111, 2367-2372. doi: 10.1073/pnas.1316278111

Gautier, L., Cope, L., Bolstad, B. M., and Irizarry, R. A. (2004). affy-analysis of Affymetrix GeneChip data at the probe level. Bioinformatics 20, 307-315. doi: 10.1093/bioinformatics/btg405

Gentleman, R. C., Carey, V. J., Bates, D. M., Bolstad, B., Dettling, M., Dudoit, S., et al. (2004). Bioconductor: open software development for computational biology and bioinformatics. Genome Biol. 5:R80. doi: 10.1186/gb-2004-5-10-r80

Grant, G. A., Hu, Z., and Xu, X. L. (2001). Specific interactions at the regulatory domain-substrate binding domain interface influence the cooperativity of inhibition and effector binding in Escherichia coli D-3-phosphoglycerate dehydrogenase. J. Biol. Chem. 276, 1078-1083. doi: 10.1074/jbc.M007512200

Hashiguchi, T., Sakakibara, Y., Hara, Y., Shimohira, T., Kurogi, K., Akashi, R., et al. (2013). Identification and characterization of a novel kaempferol sulfotransferase from Arabidopsis thaliana. Biochem. Biophys. Res. Commun. 434, 829-835. doi: 10.1016/j.bbrc.2013.04.022

Hayakawa, T., Kudo, T., Ito, T., Takahashi, N., and Yamaya, T. (2006). ACT domain repeat protein 7, ACR7, interacts with a chaperone HSP18.0-CII in rice nuclei. Plant Cell Physiol. 47, 891-904. doi: 10.1093/pcp/pcj062

Helliwell, C. A., Chin-Atkins, A. N., Wilson, I. W., Chapple, R., Dennis, E. S., and Chaudhury, A. (2001). The Arabidopsis AMP1 gene encodes a putative glutamate carboxypeptidase. Plant Cell Online 13, 2115-2125. doi: 10.1105/tpc.010146

Heyl, A., Ramireddy, E., Brenner, W. G., Riefler, M., Allemeersch, J., and Schmülling, T. (2008). The transcriptional repressor ARR1-SRDX suppresses pleiotropic cytokinin activities in Arabidopsis. Plant Physiol. 147, 1380-1395. doi: 10.1104/pp.107.115436

Heyl, A., Riefler, M., Romanov, G. A., and Schmülling, T. (2012). Properties, functions and evolution of cytokinin receptors. Eur. J. Cell Biol. 91, 246-256. doi: 10.1016/j.ejcb.2011.02.009

Hilson, P., Small, I., and Kuiper, M. T. (2003). European consortia building integrated resources for Arabidopsis functional genomics. Curr. Opin. Plant Biol. 6, 426-429. doi: 10.1016/S1369-5266(03)00086-4

Hosoda, K., Imamura, A., Katoh, E., Hatta, T., Tachiki, M., Yamada, H., et al. (2002). Molecular structure of the GARP family of plant Myb-related DNA binding motifs of the Arabidopsis response regulators. Plant Cell 14, 2015-2029. doi: $10.1105 /$ tpc.002733
Hsieh, M.-H., and Goodman, H. M. (2002). Molecular characterization of a novel gene family encoding ACT domain repeat proteins in Arabidopsis. Plant Physiol. 130, 1797-1806. doi: 10.1104/pp.007484

Huh, S. M., Noh, E. K., Kim, H. G., Jeon, B. W., Bae, K., Hu, H.-C., et al. (2010). Arabidopsis annexins AnnAtl and AnnAt4 interact with each other and regulate drought and salt stress responses. Plant Cell Physiol. 51, 1499-1514. doi: $10.1093 / \mathrm{pcp} / \mathrm{pcq} 111$

Hwang, I., Chen, H. C., and Sheen, J. (2002). Two-component signal transduction pathways in Arabidopsis. Plant Physiol. 129, 500-515. doi: 10.1104/pp. 005504

Hwang, I., and Sheen, J. (2001). Two-component circuitry in Arabidopsis cytokinin signal transduction. Nature 413, 383-389. doi: 10.1038/35096500

Imamura, A., Kiba, T., Tajima, Y., Yamashino, T., and Mizuno, T. (2003). In vivo and in vitro characterization of the ARR11 response regulator implicated in the His-to-Asp phosphorelay signal transduction in Arabidopsis thaliana. Plant Cell Physiol. 44, 122-131. doi: 10.1093/pcp/pcg014

Ishida, K., Yamashino, T., Yokoyama, A., and Mizuno, T. (2008). Three type-B response regulators, ARR1, ARR10 and ARR12, play essential but redundant roles in cytokinin signal transduction throughout the life cycle of Arabidopsis thaliana. Plant Cell Physiol. 49, 47-57. doi: 10.1093/pcp/pcm 165

Kiba, T., Aoki, K., Sakakibara, H., and Mizuno, T. (2004). Arabidopsis response regulator, $A R R 22$, ectopic expression of which results in phenotypes similar to the wol cytokinin-receptor mutant. Plant Cell Physiol. 45, 1063-1077. doi: $10.1093 / \mathrm{pcp} / \mathrm{pch} 128$

Kieber, J. J., and Schaller, G. E. (2014). "Cytokinins," in The Arabidopsis Book (The American Society of Plant Biologists), 11:e0168. doi: 10.1199/tab.0168

Kim, H. J., Kieber, J. J., and Schaller, G. E. (2012). Overlapping and lineage-specific roles for the type-B response regulators of monocots and dicots. Plant Signal. Behav. 7, 1110-1113. doi: 10.4161/psb.21293

Klein, M., and Papenbrock, J. (2004). The multi-protein family of Arabidopsis sulphotransferases and their relatives in other plant species. J. Exp. Bot. 55, 1809-1820. doi: 10.1093/jxb/erh183

Mason, M. G., Mathews, D. E., Argyros, D. A., Maxwell, B. B., Kieber, J. J., Alonso, J. M., et al. (2005). Multiple type-B response regulators mediate cytokinin signal transduction in Arabidopsis. Plant Cell 17, 3007-3018. doi: 10.1111/j.1365313X.2010.04366.x

Mitchell, R. A. C., Castells-Brooke, N., Taubert, J., Verrier, P. J., Leader, D. J., and Rawlings, C. J. (2007). Wheat Estimated Transcript Server (WhETS): a tool to provide best estimate of hexaploid wheat transcript sequence. Nucleic Acids Res. 35, W148-W151. doi: 10.1093/nar/gkm220

Mortimer, J. C., Laohavisit, A., Macpherson, N., Webb, A., Brownlee, C., Battey, N. H., et al. (2008). Annexins: multifunctional components of growth and adaptation. J. Exp. Bot. 59, 533-544. doi: 10.1093/jxb/erm344

Nemhauser, J. L., Hong, F., and Chory, J. (2006). Different plant hormones regulate similar processes through largely nonoverlapping transcriptional responses. Cell 126, 467-475. doi: 10.1016/j.cell.2006.05.050

Nogué, N., Hocart, H., Letham, D. S., Dennis, E. S., and Chaudhury, A. M. (2000). Cytokinin synthesis is higher in the Arabidopsis ampl mutant. Plant Growth Regul. 32, 267-273. doi: 10.1023/a:1010720420637

Plank, M., Wuttke, D., Van Dam, S., Clarke, S. A., and De Magalhães, J. P. (2012). A meta-analysis of caloric restriction gene expression profiles to infer common signatures and regulatory mechanisms. Mol. Biosyst. 8, 1339-1349. doi: $10.1039 / \mathrm{c} 2 \mathrm{mb} 05255 \mathrm{e}$

Ramireddy, E., Brenner, W. G., Pfeifer, A., Heyl, A., and Schmülling, T. (2013). In Planta analysis of a cis-regulatory cytokinin response motif in Arabidopsis and identification of a novel enhancer sequence. Plant Cell Physiol. 54, 1079-1092. doi: 10.1093/pcp/pct060

Rashotte, A. M., Carson, S. D., To, J. P., and Kieber, J. J. (2003). Expression profiling of cytokinin action in Arabidopsis. Plant Physiol. 132, 1998-2011. doi: 10.1104/pp.103.021436

Rashotte, A. M., Mason, M. G., Hutchison, C. E., Ferreira, F. J., Schaller, G. E., and Kieber, J. J. (2006). A subset of Arabidopsis AP2 transcription factors mediates cytokinin responses in concert with a two-component pathway. Proc. Natl. Acad. Sci. U.S.A. 103, 11081-11085. doi: 10.1073/pnas.0602038103

Rescher, U., and Gerke, V. (2004). Annexins-unique membrane binding proteins with diverse functions. J. Cell Sci. 117, 2631-2639. doi: 10.1242/ jcs.01245

Richards, S. L., Laohavisit, A., Mortimer, J. C., Shabala, L., Swarbreck, S. M., Shabala, S., et al. (2014). Annexin 1 regulates the $\mathrm{H}_{2} \mathrm{O}_{2}$-induced calcium 
signature in Arabidopsis thaliana roots. Plant J. 77, 136-145. doi: 10.1111/tpj. 12372

Sakai, H., Aoyama, T., and Oka, A. (2000). Arabidopsis ARR1 and ARR2 response regulators operate as transcriptional activators. Plant J. 24, 703-711. doi: 10.1111/j.1365-313X.2000.00909.x

Sakai, H., Honma, T., Aoyama, T., Sato, S., Kato, T., Tabata, S., et al. (2001). ARR1, a transcription factor for genes immediately responsive to cytokinins. Science 294, 1519-1521. doi: 10.1126/science.1065201

Sampedro, J., Carey, R., and Cosgrove, D. (2006). Genome histories clarify evolution of the expansin superfamily: new insights from the poplar genome and pine ESTs. J. Plant Res. 119, 11-21. doi: 10.1007/s10265-0050253-z

Schiex, T., Moisan, A., and Rouzé, P. (2001). "EuGène: a eucaryotic gene finder that combines several sources of evidence," in Computational Biology. First International Conference on Biology, Informatics, and Mathematics, JOBIM 2000, eds O. Gascuel and M.-F. Sagot (Heidelberg: Springer), 111-125.

Schneider, T. D., and Stephens, R. M. (1990). Sequence logos: a new way to display consensus sequences. Nucleic Acids Res. 18, 6097-6100. doi: 10.1093/nar/18.20.6097

Schuller, D. J., Grant, G. A., and Banaszak, L. J. (1995). The allosteric ligand site in the Vmax-type cooperative enzyme phosphoglycerate dehydrogenase. Nat. Struct. Mol. Biol. 2, 69-76. doi: 10.1038/nsb0195-69

Taniguchi, M., Sasaki, N., Tsuge, T., Aoyama, T., and Oka, A. (2007). ARR1 directly activates cytokinin response genes that encode proteins with diverse regulatory functions. Plant Cell Physiol. 48, 263-277. doi: 10.1093/pcp/pcl063
Vidaurre, D. P., Ploense, S., Krogan, N. T., and Berleth, T. (2007). AMP1 and $M P$ antagonistically regulate embryo and meristem development in Arabidopsis. Development 134, 2561-2567. doi: 10.1242/dev.006759

Wei, P.-C., Zhang, X.-Q., Zhao, P., and Wang, X.-C. (2011). Regulation of stomatal opening by the guard cell expansin AtEXPA1. Plant Signal. Behav. 6, 740-742. doi: 10.1007/s00299-010-0

Werner, T., and Schmülling, T. (2009). Cytokinin action in plant development. Curr. Opin. Plant Biol. 12, 527-538. doi: 10.1016/j.pbi.2009.07.002

Conflict of Interest Statement: The authors declare that the research was conducted in the absence of any commercial or financial relationships that could be construed as a potential conflict of interest.

Received: 14 November 2014; accepted: 13 January 2015; published online: 17 January 2015.

Citation: Brenner WG and Schmülling T (2015) Summarizing and exploring data of a decade of cytokinin-related transcriptomics. Front. Plant Sci. 6:29. doi: 10.3389/fpls. 2015.00029

This article was submitted to Plant Genetics and Genomics, a section of the journal Frontiers in Plant Science.

Copyright $\odot 2015$ Brenner and Schmülling. This is an open-access article distributed under the terms of the Creative Commons Attribution License (CC BY). The use, distribution or reproduction in other forums is permitted, provided the original author(s) or licensor are credited and that the original publication in this journal is cited, in accordance with accepted academic practice. No use, distribution or reproduction is permitted which does not comply with these terms. 